\title{
Cell-Autonomous Inhibition of $\alpha 7$-Containing Nicotinic Acetylcholine Receptors Prevents Death of Parasympathetic Neurons during Development
}

\author{
Martin Hruska and Rae Nishi \\ Department of Anatomy and Neurobiology, University of Vermont College of Medicine, Burlington, Vermont 05405
}

Neurotrophic molecules are key retrograde influences of cell survival in the developing nervous system, but other influences such as activity are also emerging as important factors. In the avian ciliary ganglion, half the neurons are eliminated between embryonic day 8 (E8) and E14, but it is not known how cell death is initiated. Because systemic application of $\alpha 7$-nicotinic acetylcholine receptor (nAChR) antagonists prevents this cell loss, we examined differences in receptor densities and responses of intracellular calcium to nicotine using the calcium-sensitive dye fura-2. In addition, we determined whether cell-autonomous inhibition of $\alpha 7$ activation in neurons prevented cell death. E8 neurons are heterogeneous with respect to $\alpha 7-\mathrm{nAChR}$ density, which leads to large increases in $\left[\mathrm{Ca}^{2+}\right]_{\mathrm{i}}$ in some neurons; E8 neurons also exhibit a slower rate of $\mathrm{Ca}^{2+}$ decay after nicotinic stimulation than $\mathrm{E} 13$ neurons. Expressing $\alpha$-bungarotoxin that is tethered to the membrane by a glycosylphosphatidylinositol linkage (GPI $\alpha$ btx) in ciliary ganglion neurons with the retroviral vector RCASBP(A) blocks increases in intracellular calcium induced by nicotine through $\alpha 7$-nAChRs and prevents neurons from dying. Expression of GPI $\alpha$ btx in surrounding non-neural tissues, but not in neurons, does not prevent cell loss. Furthermore, the GPI $\alpha$ btx is not efficiently expressed in the accessory oculomotor neurons, eliminating preganglionic inputs as another site for action of the antagonist. These results support the hypothesis that cholinergic inputs facilitate cell death in the developing autonomic nervous system by activating $\alpha 7$-nAChRs, possibly by leading to increases in intracellular calcium that exceed the threshold for cell survival.

Key words: glycosylphosphatidylinositol; $\alpha$-bungarotoxin; RCAS; calcium imaging; ciliary ganglion; retrovirus

\section{Introduction}

The phenomenon of cell death of postmitotic neurons in the developing vertebrate nervous system has been well described, but the means by which cell death is induced are not well understood (Oppenheim, 1991). Up to $70 \%$ of neurons are lost at the time of synapse formation with their targets, during which neurons are dependent on target-derived factors for survival (Davies, 1996). The neurotrophic hypothesis proposes that neurons die because they fail to compete effectively for a limited amount of trophic factor in the target tissue. Both gain- and loss-of-function studies show that many target-derived factors are essential for supporting neuronal survival (Snider, 1994); however, neurons integrate trophic support from more than one source (target and glia), and to do this, they must enter the competition with some advantage involving cell-to-cell differences in intrinsic factors, such as surface receptor expression (for review, see Pettmann and Henderson, 1998). This suggests that the trophic requirements of

\footnotetext{
Received July 5, 2007; revised Aug. 17, 2007; accepted Sept. 4, 2007.

This work was supported by National Institutes of Health Grants NS25767 and DA017784 (R.N.). Imaging was supported by the Centers of Biomedical Research Excellence Program of the National Center for Research Resources (P20 RR16435), and flow cytometry was supported by the Vermont Cancer Center. We thank Drs. Ines Ibanez-Tallon and Nathanial Heintz for providing us with the GPI- $\alpha$ btx construct. We are also grateful to Drs. Rodney Parsons, Victor May, Jennifer Straub, and Steven Straub for comments on our manuscript.

Correspondence should be addressed to Dr. Rae Nishi, Department of Anatomy and Neurobiology, 149 Beaumont Avenue, Burlington, VT 05405. E-mail: rnishi@uvm.edu.

DOI:10.1523/JNEUROSCI.3057-07.2007

Copyright $\odot 2007$ Society for Neuroscience $\quad$ 0270-6474/07/2711501-09\$15.00/0
}

neurons are more complex and other signals may also be involved in controlling cell death (Eisen and Melancon, 2001).

The ciliary ganglion, a parasympathetic ganglion that innervates the iris, ciliary muscle, and choroidal vasculature in the avian eye (Marwitt et al., 1971), undergoes a period of targetdependent cell loss between embryonic day 8 (E8) and E14 (Landmesser and Pilar, 1974b). However, virtually all ciliary ganglion neurons are rescued from dying by daily application of $\alpha 7$ subunit-containing nicotinic acetylcholine receptor (nAChR)specific antagonists to the chorioallantoic membrane between E8 and E14 without changes in trophic factor availability or access at target tissues (Meriney et al., 1987; Bunker and Nishi, 2002). This suggests that activation of $\alpha 7$-nAChRs can facilitate cell death independently of the competition for target-derived factors. However, the site at which these antagonists act is not clear because they were delivered throughout the entire chicken embryo.

$\alpha 7$-nAChRs are cation-selective channels that are highly expressed together with heteromeric nAChRs containing $\alpha 3, \alpha 5, \beta 4$, and sometimes $\beta 2$ subunits on ciliary ganglion neurons, where they mediate excitatory transmission (Zhang et al., 1996; Chang and Berg, 1999). In addition, $\alpha 7$-nAChRs have high relative permeability to $\mathrm{Ca}^{2+}$ that rivals that of NMDA receptors, but unlike NMDA receptors, $\alpha 7$-nAChRs can mediate $\mathrm{Ca}^{2+}$ influx at resting or hyperpolarized potentials (for review, see Role and Berg, 1996). This feature enables them to influence a variety of $\mathrm{Ca}^{2+}$-dependent events, including gene expression, neurite retraction, axonal pathfinding, 
and cell death (Pugh and Berg, 1994; Zheng et al., 1994; Berger et al., 1998; Chang and Berg, 2001; Liu et al., 2006).

This study was undertaken to determine whether activation of $\alpha 7$-nAChRs on ciliary ganglion neurons causes cell death. To do this, we used $\alpha$-bungarotoxin ( $\alpha$ btx) tethered to the membrane by glycosylphosphatidylinositol (GPI) linkage (Ibanez-Tallon et al., 2004), to determine whether cell-autonomous inhibition of $\alpha 7$-nAChRs prevents both ciliary and choroid neurons from dying. We also examine differences in $\mathrm{Ca}^{2+}$ signaling between neurons before cell death and propose a possible mechanism of $\alpha 7$ nAChR-induced cell death through $\mathrm{Ca}^{2+}$ overload. Our findings highlight the importance of nontraditional roles of nAChRs during neural development.

\section{Materials and Methods}

Isolation of neurons. Ciliary ganglia were isolated and dissociated for imaging, staining, and flow cytometry from E6 to E10 embryos as described previously (Nishi, 1996). E13 ciliary ganglia were dissociated by incubating in Earle's balanced salt solution (EBSS) containing $1 \mathrm{mg} / \mathrm{ml}$ collagenase type 2 (catalog \#4176; Worthington, Lakewood, NJ), 1 $\mathrm{mg} / \mathrm{ml}$ hyaluronidase (catalog \#2592; Worthington), and $10 \mathrm{mg} / \mathrm{ml}$ bovine serum albumin (Sigma, St. Louis, MO) for $15 \mathrm{~min}$ at $37^{\circ} \mathrm{C}$. The activity of the proteases was terminated by dilution, then the supernatant was removed and ganglia were incubated in EBSS containing $3 \mathrm{mg} / \mathrm{ml}$ trypsin (catalog $\# 3703$; Worthington) for $3 \mathrm{~min}$ at $37^{\circ} \mathrm{C}$. Ciliary ganglia were triturated until completely dissociated. After dissociation, cells were preplated on the plastic surface for $30 \mathrm{~min}$ at $37^{\circ} \mathrm{C}$ to remove adherent cells (fibroblast and glia). Neurons were plated on poly-D-lysine/ laminin-coated coverslips in complete medium consisting of DMEM (Invitrogen, Carlsbad, CA) containing 10\% (v/v) heat-inactivated horse serum (Invitrogen), 2\% (v/v) fetal calf serum (Atlanta Biologicals, Lawrenceville, GA), $2 \%$ (v/v) chicken eye extract with $50 \mathrm{U} / \mathrm{ml}$ penicillin, 50 $\mathrm{mg} / \mathrm{ml}$ streptomycin, and $2 \mathrm{~mm}$ glutamine (Invitrogen). Neurons were used for staining or calcium imaging after allowing them to attach to the coverslip for $2 \mathrm{~h}$ after plating. Alternatively, acutely isolated neurons were incubated with $\alpha$ btx-Alexa 488 or Q211 and immediately processed for flow cytometry as described below.

Immunostaining and live cell labeling. Dissociated E8 or E13 neurons were incubated while alive with Alexa 488 -conjugated $\alpha \mathrm{btx}$ (Invitrogen), diluted 1:500 in complete medium for $30 \mathrm{~min}$ at $37^{\circ} \mathrm{C}$, or with rabbit anti- $\alpha$ btx, diluted 1:1000 in complete medium for $30 \mathrm{~min}$ on ice, to label only cell-surface molecules. After the incubation, neurons were washed three times in EBSS and fixed in Zamboni's fixative (4\% paraformaldehyde and $15 \%$ picric acid in $0.1 \mathrm{~m}$ sodium phosphate, $\mathrm{pH} 7.4$ ) for $2 \mathrm{~h}$ at $4^{\circ} \mathrm{C}$. Coverslips were washed with PBS ( $137 \mathrm{~mm} \mathrm{NaCl}$ and $20 \mathrm{~mm}$ sodium phosphate, $\mathrm{pH} 7.4$ ), blocked overnight in blocking buffer [PBS plus $0.5 \%$ $(\mathrm{v} / \mathrm{v})$ Triton X-100 containing $5 \%(\mathrm{v} / \mathrm{v})$ horse serum] at $4^{\circ} \mathrm{C}$, and incubated overnight in primary antibodies. Secondary antibodies were incubated for $1-2 \mathrm{~h}$ at room temperature.

Tissues were prepared for immunohistochemistry as follows. Ciliary ganglia and brainstems from E14 embryos were harvested, fixed in Zamboni's fixative for $48 \mathrm{~h}$ at $4^{\circ} \mathrm{C}$, washed, and equilibrated in $30 \%$ sucrose at $4^{\circ} \mathrm{C}$. Tissue was embedded in Microm cryo-embedding compound (Richard Allen Scientific, Kalamazoo, MI), sectioned on a Microm HM 560 cryostat (Richard Allen Scientific) at $30 \mu \mathrm{m}$, and collected on Superfrost Plus slides (Fisher Scientific, Pittsburgh, PA). Sections were postfixed in Zamboni's fixative vapors for $15 \mathrm{~min}$ at $37^{\circ} \mathrm{C}$, submerged in Zamboni's fixative for an additional $15 \mathrm{~min}$ at $25^{\circ} \mathrm{C}$, washed in PBS, and blocked. Primary antibodies were incubated overnight at $4^{\circ} \mathrm{C}$, and secondary antibodies were incubated $2 \mathrm{~h}$ at room temperature.

Primary antibodies and the dilutions in blocking buffer at which they were used were as follows: anti-mouse AMV-3C2 (Developmental Studies Hybridoma Bank, Iowa City, IA), which recognizes a viral p19 gag expressed by avian sarcoma and leukemia viruses (Potts et al., 1987), at 1:10; mouse anti-Islet-1, which recognizes a transcription factor expressed in ciliary ganglion neurons (Lee et al., 2001), at 1:100 dilution of the culture supernatant (prepared in the Nishi laboratory from clone
39.4D5; Developmental Studies Hybridoma Bank); mouse anti-Hu C/D (Invitrogen), which recognizes a neuron-specific RNA-binding protein (Marusich and Weston, 1992; Lee et al., 2001), at 1:250 dilution of the culture supernatant; rabbit anti-p27gag (SPAFAS, Norwich, CT), which recognizes avian sarcoma gag p27 (Wang et al., 1976), at 1:1000; rat anti-somatostatin (product number YMC1020; Accurate Chemical and Scientific Corporation, Westbury, NY) diluted 1:100; and rabbit anti$\alpha$ btx [a generous gift from Dr. J. Sanes, Washington University, St. Louis, MO (now at Harvard University, Cambridge, MA)] at 1:1000, the specificity of which is shown in supplemental Figure 1 (available at www. jneurosci.org as supplemental material).

Secondary antibodies were as follows: biotinylated anti-mouse (Vector Laboratories, Burlingame, CA) at 1:250; biotinylated anti-rabbit (Vector Laboratories) at 1:250; goat anti-mouse Cy3 (Jackson ImmunoResearch, West Grove, PA) at 1:750; goat anti-rabbit Alexa 488 (Invitrogen) at 1:750; and goat anti-rat Cy3 (Jackson ImmunoResearch) at 1:750. Images of dissociated neurons were acquired with a $60 \times$ objective on a DeltaVision (Olympus IX70) deconvolution microscope (Applied Precision, Issaquah, WA) using a CoolSNAP HQ CCD camera (Photometrics, Tucson, AZ). Image stacks were deconvolved using softWoRx image analysis software version 3.5.1 (Applied Precision, Issaquah, WA). Images of ciliary ganglia and midbrain were acquired with a $20 \times$ objective using a Nikon (Melville, NY) C1 confocal scanner attached to a Nikon Eclipse E800 microscope (Micro Video Instruments, Avon, MA).

Flow cytometry. Dissociated neurons were labeled live with 1:500 $\alpha$ btx-Alexa 488 and 1:3000 mouse anti-Q211 (kindly provided by Dr. H. Rohrer, Max Planck Institute for Brain Research, Frankfurt, Germany), which recognizes a neuron-specific ganglioside (Rohrer et al., 1985). Q211 immunoreactivity was visualized with goat $\mathrm{F}\left(\mathrm{ab}^{\prime}\right) 2$ anti-mouse IgG conjugated to PE-Cy5.5 (Caltag Laboratories, Burlingame, CA) diluted 1:200. At each developmental stage examined, 40,000 cells were analyzed for their surface $\alpha 7$-nAChR levels by flow cytometry using a Coulter (Miami, FL) Epics XL Analyzer. Generated scatter plots indicated the relative levels of $\alpha$ btx-Alexa 488 binding of all Q211 positive cells.

Expression of GPI $\alpha$ btx with a viral vector. An $\alpha$ btx that is tethered to the membrane via a GPI linkage (GPI $\alpha$ btx) was a gift from Drs. I. IbanezTallon and N. Heintz (Rockefeller University, New York, NY) (IbanezTallon et al., 2004). The GPI $\alpha$ btx sequence was cloned into the Slax13NCO1 shuttle vector using 5' NcoI and 3' EcoRI sites (Morgan and Fekete, 1996); the insert was removed from Slax13NCO1 by cutting with ClaI and was cloned into the avian retroviral vector RCASBP(A) (Federspiel and Hughes, 1997). Infective RCASBP(A)-GPI- $\alpha$ btx viral particles were generated by transfecting DF-1 chicken fibroblast cells with $800 \mathrm{ng}$ of RCASBP(A)-GPI $\alpha$ btx plasmid using TransIT-LT transfection reagent (Mirus Bio Corporation, Madison, WI). Conditioned media containing viral stocks collected from DF- 1 cells were concentrated $\sim 20$-fold by ultracentrifugation at $90,000 \times g$ at $4^{\circ} \mathrm{C}$ for $3 \mathrm{~h}$ (Morgan and Fekete, 1996). Concentrated stocks were titered by limiting dilution and infectivity of cells as measured by staining with p27gag antibody. Stocks with a concentration of $>10^{8}$ infectious particles per milliliter were used for in vivo injection. Viral particles $(60-120 \mathrm{nl})$ were injected into the mesencephalic enlargement of the neural tube of Hamburger/Hamilton stage $8-9$ or stage $10-13$ embryos using a Nanoject microinjector (Drummond Scientific, Broomall, PA). The shells were sealed with a glass coverslip and sterile vacuum grease and incubated at $37^{\circ} \mathrm{C}$ to the desired stage.

Calcium imaging. Acutely isolated ciliary ganglion neurons were loaded with fura-2 AM (Invitrogen) dissolved in DMSO at a final concentration of $5 \mu \mathrm{M}$ with $2 \%$ Pluronic F-127 (Invitrogen). Neurons were loaded at room temperature for $30 \mathrm{~min}$ in the dark. Calcium signals were recorded by exposure to alternating wavelength ( 340 and $380 \mathrm{~nm}, 50 \mathrm{~ms}$ ) generated by a xenon light source and a Lambda DG-4 ultra high-speed wavelengths switcher (Sutter Instruments, Novato, CA). Fluorescent responses were recorded using an Orca-ER digital camera (Hammatsu, Bridgewater, NJ). Paired 340/380 ratio images were acquired at $4 \mathrm{~s}$ intervals with Metaflour 5.0r5 software (Molecular Devices, Downingtown, PA). Drugs were dissolved in chicken physiological buffer (in mM: 145 $\mathrm{NaCl}, 5.4 \mathrm{KCl}, 0.8 \mathrm{MgCl}_{2}, 5.4 \mathrm{CaCl}_{2}$, 5 glucose, and 13 HEPES, pH 7.4). 
Voltage-gated sodium and calcium channels were blocked by supplementing the perfusion medium with $600 \mathrm{~nm}$ tetrodotoxin (TTX; Tocris, Ellisville, MO) and $200 \mu \mathrm{m}$ cobalt chloride (Sigma), respectively. A concentration of $10 \mu \mathrm{M}$ nicotine (Sigma) was applied for $20 \mathrm{~s}$ to activate nAChRs. $\alpha 7$-nAChRs were inhibited by perfusing the neurons with 50 nм $\alpha$-methyllycaconitine citrate hydrate (MLA) (Sigma) for $1 \mathrm{~min}$ or preincubating with $50 \mathrm{~nm} \alpha$ btx (Sigma) for $30 \mathrm{~min}$ at $25^{\circ} \mathrm{C}$. Heteromeric $\alpha 3 / \alpha 5 / \beta 4 / \beta 2\left(\alpha 3^{\star}\right)$-nAChRs were blocked by perfusing neurons for 1 min with $5 \mu \mathrm{M}$ dihydro- $\beta$-erythroidine hydrobromide (DH $\beta \mathrm{E}$; Sigma). On completion of these experiments, the extent of dye loading was determined by activating voltage-gated calcium channels with a highpotassium perfusion solution $(25 \mathrm{~mm} \mathrm{KCl}$, with no TTX or cobalt chloride).

Analysis of $\mathrm{Ca}^{2+}$ imaging data. After the initial recordings were performed, background was subtracted from every image acquired and new ratios were calculated using the Metafluor 5.0r5 software. The ratios were then exported into the Microsoft (Redmond, WA) Excel spreadsheet, and all the calculations were performed using Microsoft Excel. For the calculation of $\mathrm{Ca}^{2+}$ decay rates, traces were normalized so that the baseline was always 0 and the peak calcium signal was always 1 , using the equation $\left(F-F_{0}\right) / F_{\text {peak }}$. Baseline fluorescence $\left(F_{0}\right)$ was subtracted from the fluorescence at every time point $(F)$. This value was then divided by peak amplitude fluorescence $\left(F_{\text {peak }}\right)$. This allowed us to observe changes in the rate of $\mathrm{Ca}^{2+}$ decay between individual neurons.

Design-based stereology. Serially sectioned ciliary ganglia (cut at 30 $\mu \mathrm{m}$ ) were prepared for designed-based stereology as described previously (Bunker and Nishi, 2002), and Islet-1-positive nuclei (representing all neurons) together with somatostatin-positive cell bodies (representing all choroid neurons) were counted using the Optical Dissector Probe of Stereo Investigator (MBF Biosciences, Williston, VT) in conjunction with a Nikon Optiphot 2 microscope with a Hitachi (Tokyo, Japan) HVC20 camera, Heidenhahn focus encoder, and a motorized, computer-driven $\mathrm{X}, \mathrm{Y}, \mathrm{Z}$ stage (all microscope attachments provided by MBF Biosciences). To avoid inaccuracies caused by cutting artifacts and double counting between adjacent sections, an upper guard of $4 \mu \mathrm{m}$ and a lower guard of $7 \mu \mathrm{m}$ were used (Bunker and Nishi, 2002). Spacing between sampling sites (grid size) was set such that 13-15 sampling sites were counted per section, which yielded $100-300$ objects per each ciliary ganglion. The number of ciliary neurons was calculated by subtracting the number of somatostatin-positive neurons from the total number of neurons per ciliary ganglion (Bunker and Nishi, 2002).

\section{Results}

\section{Immature ciliary ganglion neurons express heterogeneous} levels of $\alpha 7-n A C h R s$

If cell death in the ciliary ganglion is triggered in some neurons but not others in vivo between E7 and E9 by excessive signaling through $\alpha 7$ subunit-containing nAChRs, then there should be heterogeneity in $\alpha 7$-nAChR expression between individual neurons, in which the neurons with high levels of surface $\alpha 7$-nAChRs would be especially at risk to die from high $\mathrm{Ca}^{2+}$ influx through these receptors. To label surface $\alpha 7$-nAChRs, $\alpha$ btx-Alexa 488 was bound to live ciliary ganglion neurons at E8. Individual E8 neurons exhibit different intensities of staining with $\alpha$ btx-Alexa 488 (Fig. $1 A$ ). One example of $\alpha 7$-nAChR heterogeneity is shown in Figure $1 A$, where a neuron indicated by arrow labels brightly with $\alpha$ btx-Alexa 488 , whereas neighboring neurons display a low level of $\alpha$ btx-Alexa 488 binding (Fig. $1 A$, arrowhead).

At E13, we identified acutely isolated neurons as choroid or ciliary based on somatostatin immunoreactivity (Epstein et al., 1988; Coulombe et al., 1993). Both ciliary and choroid neurons express high levels of surface $\alpha 7$-nAChRs (Fig. $1 B, C$ ). Moreover, $\alpha 7$-nAChRs on somatostatin-negative ciliary neurons are found tightly clustered on somatic spines at this developmental stage, which is another sign of maturation (Fig. $1 B$, arrows) (Shoop et al., 1999). Choroid neurons that express somatostatin do not show $\alpha 7$-nAChR clustering (Fig. 1C). Qualitatively, the intensity
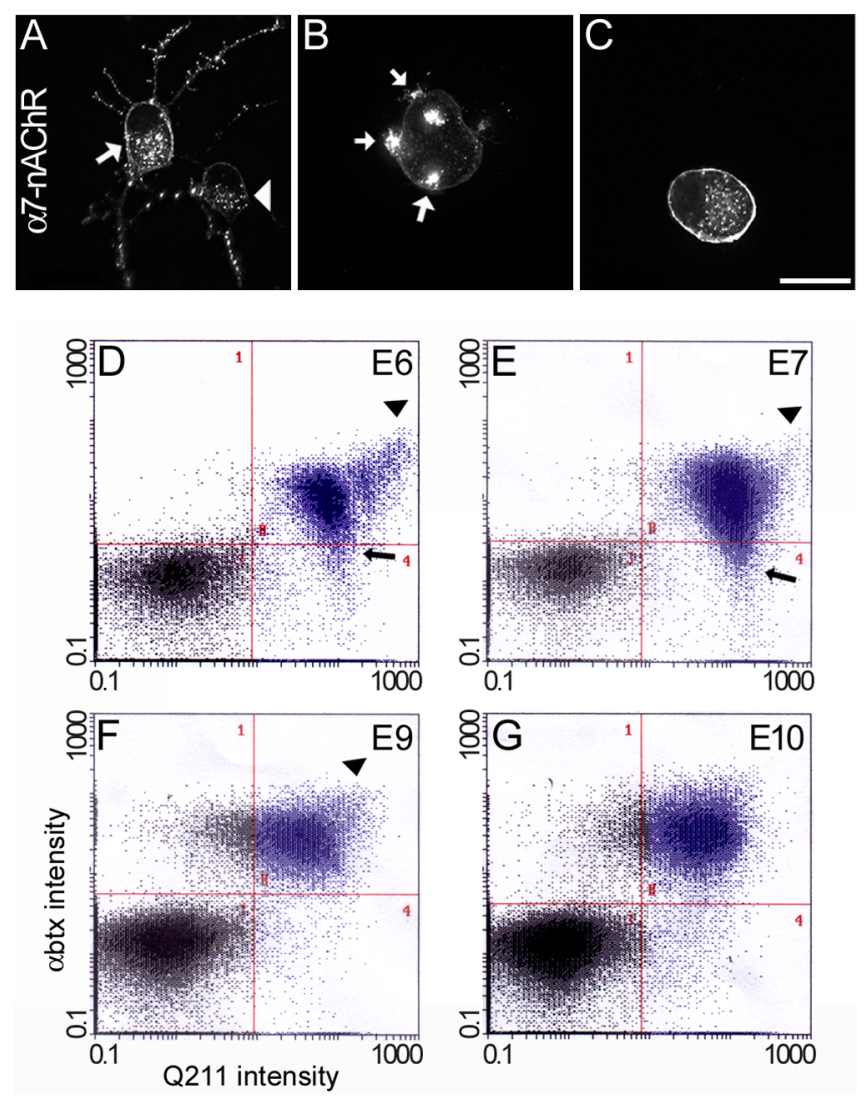

Figure 1. Cell-surface $\alpha 7-n A C h R s$ on developing ciliary ganglion neurons. $\boldsymbol{A}-\mathbf{G}$, Acutely dissociated neurons were incubated while alive with $\alpha$ btx-Alexa 488 and then imaged $(\boldsymbol{A}-\boldsymbol{C})$ or subjected to flow cytometry $(\boldsymbol{D}-\boldsymbol{G})$. E13 neurons $(\boldsymbol{B}, \boldsymbol{C})$ were fixed and stained for somatostatin immunoreactivity to identify choroid neurons. $A, A t E 8$, some neurons express a large number of $\alpha 7$-nAChRs (arrow), whereas others have very low numbers (arrowhead). B, At E13, $\alpha 7-n A C h R s$ are clustered on ciliary neurons (arrows). C, E13 choroid neurons have evenly distributed receptors on their cell surface. Similar results were obtained from three additional experiments. Images were captured as optical stacks on an 0lympus epifluorescence microscope and deconvolved on a DeltaVision workstation. Scale bar, $15 \mu \mathrm{m}$. D-G, Acutely dissociated E6 -E10 ciliary ganglion neurons were colabeled with the neuronal-specific Q211 antibody and $\alpha$ btx-Alexa 488 , and at each age, 40,000 cells were analyzed by flow cytometry. Axes for all four graphs are identical to those labeled in $\boldsymbol{F}$. Cells in the upper right quadrant are neurons (Q211 positive) that express $\alpha 7$-nAChRs ( $\alpha$ btx binding). D, E, The majority of neurons label at a tightly clustered level of $\alpha$ btx intensity; however, atE6 $(\boldsymbol{D})$ and E7 (E), there is a subpopulation of cells with high $\alpha$ btx-Alexa 488 binding (arrowhead) and a subpopulation with very low $\alpha$ btx-Alexa 488 binding (arrow).F, At E9, all neurons bind $\alpha$ btx, but few neurons still exhibit high $\alpha$ btx binding (arrowhead). G, By E10, virtually all neurons have relatively homogeneous $\alpha$ btx-Alexa 488 binding.

of staining with $\alpha$ btx-Alexa 488 does not differ between individual E13 neurons of each population.

To survey the number of neurons exhibiting different levels of $\alpha$ btx-Alexa 488 binding at various stages of development across ganglia, we used flow cytometry (Fig. $1 D-G$ ). Neurons were distinguished from non-neuronal cells by immunoreactivity to Q211, an antibody that recognizes a neuron-specific ganglioside shortly after neural progenitors have commenced differentiation (Rohrer et al., 1985). At E6 and E7, neurons (Q211-positive cells) are very heterogeneous with respect to their surface $\alpha$ btx binding, as can be seen by the large amount of scatter in $\alpha$ btx labeling intensities (Fig. 1D,E). By E9, the Q211-positive cells with little or no $\alpha$ btx binding have all begun to express $\alpha 7$-nAChRs, and a few neurons still display very high $\alpha$ btx binding (Fig. $1 F$, arrowhead). However, by E10, $\alpha$ btx binding is much more homogeneous than at E6 and E7 (Fig. 1G). The loss of Q211 immunore- 
activity, as seen by the spread of $\alpha$ btx-positive cells into the upper left quadrant (Fig. $1 F, G$ ), is a normal progression of Q211 staining that we have observed as neurons mature.

Because $\alpha 7$-nAChRs have a high relative permeability to calcium equal to that of NMDA receptors (Role and Berg, 1996), we tested whether the heterogeneity in surface $\alpha 7$-nAChRs observed at E8 leads to larger increases in intracellular $\mathrm{Ca}^{2+}$ in some neurons versus others. Neurons were imaged using the ratiometric dye fura-2, and $10 \mu \mathrm{M}$ nicotine was applied by perfusion to activate the maximum number of nAChRs in all the neurons imaged by the microscope. By doing so, we could collect data on a large number of neurons per experiment, which is not possible by single-cell electrophysiology. To ensure that only nicotinic $\mathrm{Ca}^{2+}$ responses were measured, $200 \mu \mathrm{M} \mathrm{CoCl}_{2}$ and $600 \mathrm{nM}$ TTX were added to the perfusion buffer to inhibit voltage-gated calcium and sodium channels, respectively (see Materials and Methods).

First, we tested whether neurons could recover nAChR sensitivity after nicotine application so that the efficacy of antagonists could be tested. After the first application of nicotine (Nic1), we washed cells for $5 \mathrm{~min}$ and then perfused nicotine again (Nic2) (Fig. 2A). The peak amplitude of the $\mathrm{Ca}^{2+}$ response after the second stimulation was not significantly different from the initial application of nicotine (Fig. $2 B$ ). Therefore, in all subsequent experiments, we washed for at least $5 \mathrm{~min}$ after the initial application of nicotine before we applied nicotine together with nicotinic antagonists. The response elicited by nicotine could be significantly reduced by $50 \mathrm{~nm}$ MLA, an antagonist known to selectively block $\alpha 7$-nAChRs on ciliary ganglion neurons at this concentration (Alkondon et al., 1992) (Fig. 2C) $(p<0.0001$, one-way ANOVA; $n=34$ neurons). The residual response was completely blocked with a mixture containing $50 \mathrm{nM}$ MLA and 5 $\mu \mathrm{M} \mathrm{DH} \beta \mathrm{E}$ (Fig. $2 C$, compare MLA with $\mathrm{DH} \beta \mathrm{E} / \mathrm{MLA})(p<$ 0.0001 , one-way ANOVA; $n=30$ neurons), which completely blocks transmission through the ciliary ganglion (Bertrand et al., 1992; Liu et al., 2006).

We then examined whether there are differences in $\alpha 7$ nAChR-induced $\mathrm{Ca}^{2+}$ influx between ciliary ganglion neurons isolated at different stages of development. To determine the $\mathrm{Ca}^{2+}$ influx mediated by $\alpha 7-\mathrm{nAChR}, \mathrm{Ca}^{2+}$ responses obtained in the presence of the $\alpha 7-n A C h R-s p e c i f i c$ antagonist MLA were subtracted from the total $\mathrm{Ca}^{2+}$ responses to $10 \mu \mathrm{M}$ nicotine. When E8 neurons are stimulated with nicotine, the elicited $\mathrm{Ca}^{2+}$ responses have a broad distribution (Fig. 2D), demonstrating that individual E8 neurons exhibit variability in $\mathrm{Ca}^{2+}$ influx through $\alpha 7$-nAChRs. Compared with E8 neurons, $\alpha 7$-specific $\mathrm{Ca}^{2+}$ responses at $\mathrm{E} 9$ are skewed to the left with the majority of responses clustered around the mean (Fig. $2 D$ ). The mean of $\alpha 7$-nAChR-specific $\mathrm{Ca}^{2+}$ responses at E9 is significantly smaller compared with E8 neurons $(p<0.0002$, Student's $t$ test; E8: $0.09 \pm 0.007, n=41$; E9: $0.06 \pm 0.004, n=80)$. At E13, which is near the end of the cell death period, only half of the ciliary ganglion neurons display increases in intracellular calcium in response to perfused nicotine, despite the fact that all of them respond to high $\mathrm{K}^{+}$, indicating that all cells are equally loaded with fura-2. Of the ones that respond, intracellular $\mathrm{Ca}^{2+}$ decays to baseline at much faster rate than in neurons isolated at E8 (before onset of neuronal loss) (Fig. 2E). At $\mathrm{E} 8$, the rate of $\mathrm{Ca}^{2+}$ decay can be fitted with a single exponential $(\tau=48.9 \pm 0.98 \mathrm{~s})$, whereas the rate of $\mathrm{Ca}^{2+}$ decay at $\mathrm{E} 13$ can be fitted with double exponential, with initial fast decay $\left(\tau_{1}=17.5 \pm 0.42 \mathrm{~s}\right)$ and later slower decay $\left(\tau_{2}=175.6 \pm\right.$ $91.4 \mathrm{~s})$, suggesting that an additional mechanism for sequestering intracellular calcium has developed. Treatment with
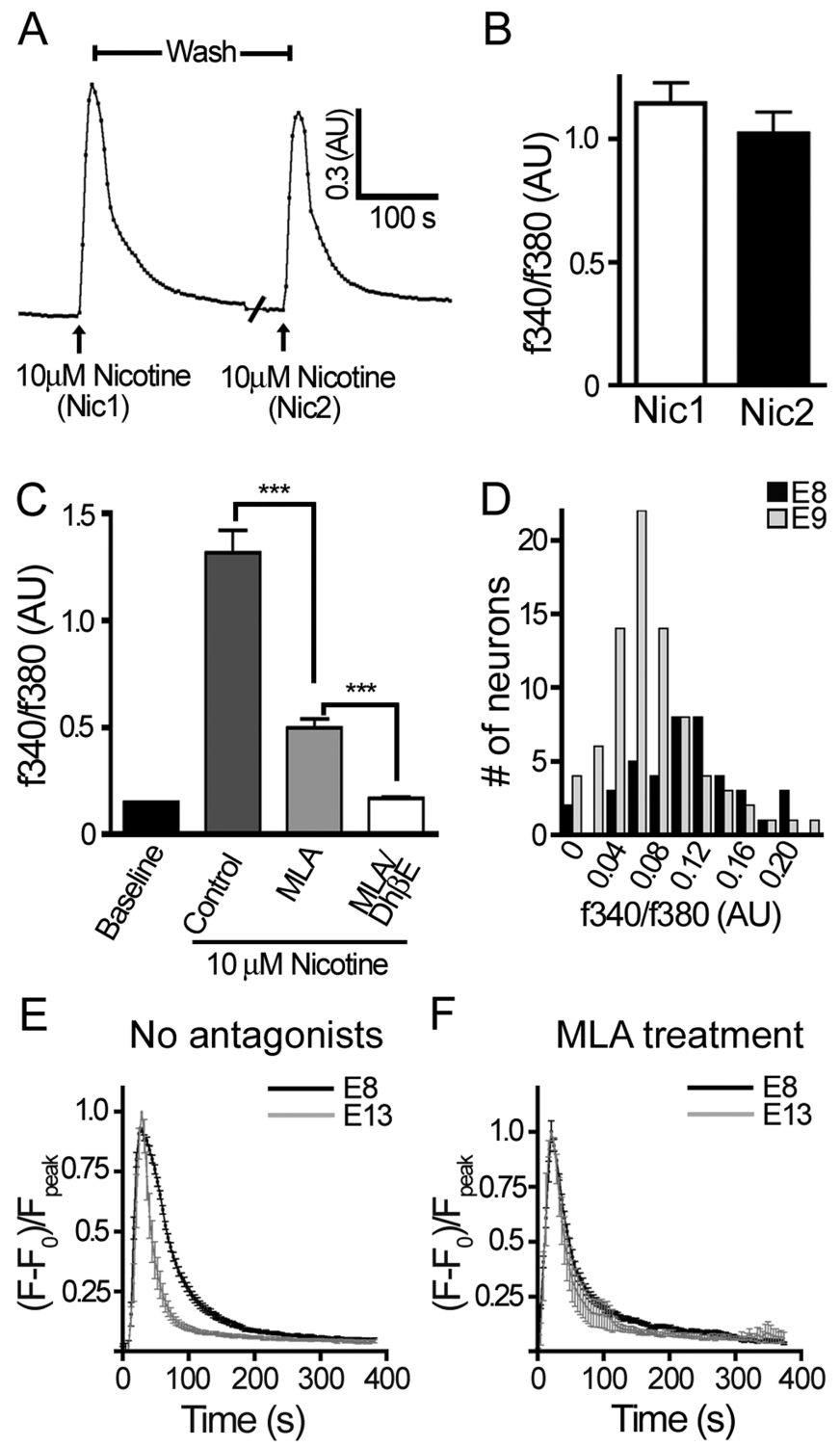

Figure 2. Calcium influx through $\alpha 7$-nAChRs during ciliary ganglion development. Acutely dissociated E8 neurons were loaded with the ratiometric calcium indicator dye fura-2 and stimulated by perfusing with $10 \mu \mathrm{m}$ nicotine. $\boldsymbol{A}$, Cell responses to two applications of nicotine (Nic1 and Nic2) for $20 \mathrm{~s}$ with $5 \mathrm{~min}$ washout between them are shown. $\boldsymbol{B}$, The mean Nic1 and Nic2 $\mathrm{Ca}^{2+}$ responses are not significantly different, indicating that $\mathrm{nAChRs}$ recover from desensitization during the 5 min washout ( $p>0.05$, Student's $t$ test; $n=14$ neurons). C, Nicotineinduced $\mathrm{Ca}^{2+}$ response is significantly reduced by treatment with MLA ( $n=34$ neurons; ${ }^{* * *} p<0.0001$, one-way ANOVA) and completely eliminated by treatment with MLA and $\mathrm{DH} \beta \mathrm{E}$ ( $n=30$ neurons; $p<0.0001$, one-way ANOVA). $\boldsymbol{D}$, At E8, $\alpha 7$-nAChR-specific $\mathrm{Ca}^{2+}$ responses are distributed over a wide range (mean, $0.09 \pm 0.007 ; n=41$ ), whereas $\mathrm{Eg} \mathrm{Ca}^{2+}$ responses are skewed to the left with majority of $\mathrm{Ca}^{2+}$ responses clustered around mean $(0.06 \pm 0.004 ; n=80)$. Compared with $E 9$ neurons, 20 s application of $10 \mu \mathrm{m}$ nicotine induces larger increases in $\left[\mathrm{Ca}^{2+}\right]_{\mathrm{i}}$ in E8 neurons $\left(p<0.0002\right.$, Student's $t$ test). $\boldsymbol{E}, \boldsymbol{F}$, The rate of $\mathrm{Ca}^{2+}$ decay was measured in $\mathrm{E} 8$ and $\mathrm{E} 13$ acutely dissociated neurons. Traces were normalized to the percentage of peak $\mathrm{Ca}^{2+}$ amplitude to detect changes in the time course of $\mathrm{Ca}^{2+}$ decay. $\boldsymbol{E}$, At $\mathrm{E} 8, \mathrm{Ca}^{2+}$ decays back to baseline at a much slower rate than at E13 (E8: $\tau=48.9 \pm 0.98 \mathrm{~s}, n=$ 33 from 3 different ganglia; E13: $\tau_{1}=17.5 \pm 0.42 \mathrm{~s}, \tau_{2}=175.6 \pm 91.4 \mathrm{~s}, n=6$ from 5 different ganglia). $\boldsymbol{F}$, Treatment with MLA eliminates the differences in the rate of $\mathrm{Ca}^{2+}$ decay between E8 and E13 neurons. Values represent mean \pm SEM. AU, Arbitrary units.

MLA eliminates differences in the rate of $\mathrm{Ca}^{2+}$ decay between E8 and E13 neurons; at both stages, the rate of $\mathrm{Ca}^{2+}$ decay can be fitted with a double-exponential equation (Fig. $2 F)\left(\right.$ E8: $\tau_{1}=27.9 \pm$ $\left.0.0005 \mathrm{~s}, \tau_{2}=1014.1 \mathrm{~s} ; \mathrm{E} 13: \tau_{1}=20.7 \pm 1.56 \mathrm{~s}, \tau_{2}=78.8 \pm 26.1 \mathrm{~s}\right)$. 
A

\begin{tabular}{|c|c|c|c|}
\hline signal |FLAG & $\alpha$-btx & GPI anchor & STOP \\
\hline
\end{tabular}
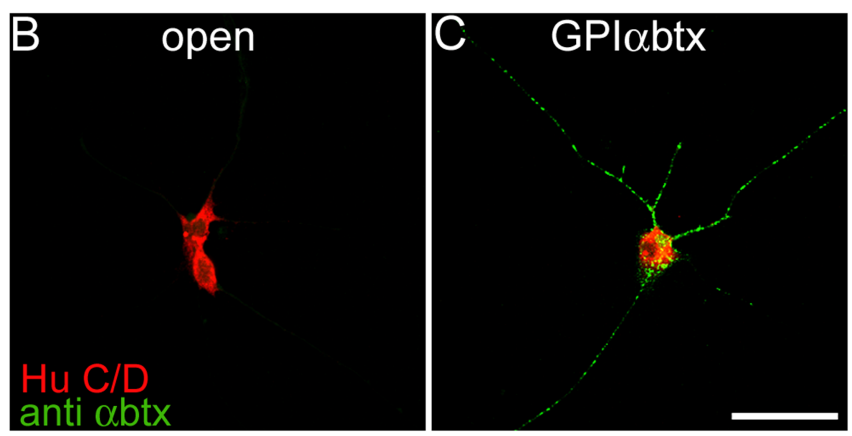

D

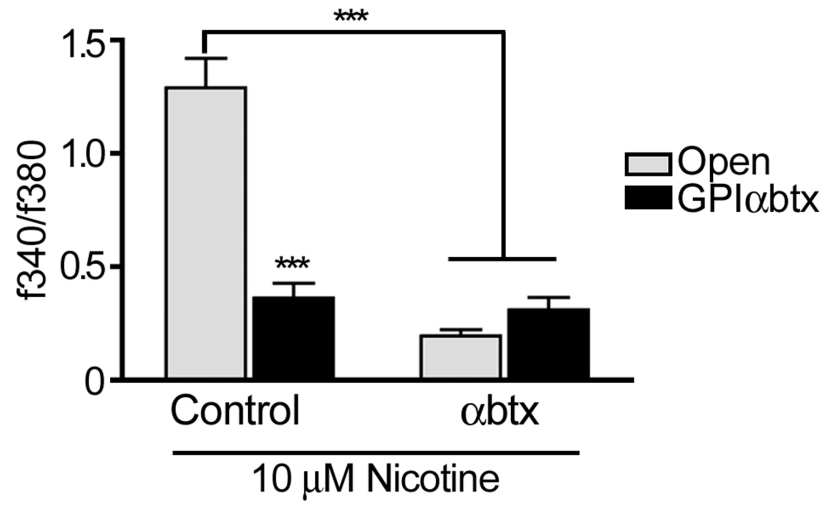

Figure 3. GPI $\alpha$ btx expression in ciliary ganglion neurons after injection with RCASBP(A) retrovirus. $\boldsymbol{A}$, Diagram of GPl $\alpha$ btx cassette, containing the mature $\alpha$ btx sequence linked to the lynx 1 consensus sequence (seq) for addition of a GPI anchor. $\boldsymbol{B}, \boldsymbol{C}$, Dissociated E8 ciliary ganglion neurons infected with control ( $\boldsymbol{B}$, open) RCASBP(A) or RCASBP(A)-GPI $\alpha$ btx $(\boldsymbol{C})$ were incubated with anti- $\alpha$ btx while alive at $4^{\circ} \mathrm{C}$ to label cell-surface $\alpha$ btx (green), fixed, and colabeled with neuronal-specific Hu C/D antibody (red) to demonstrate efficacy of infection. Only neurons infected with the RCASBP(A)-GPI $\alpha$ btx are labeled with the antibody. Scale bar, $10 \mu \mathrm{m}$. D GPI $\alpha$ btx-infected neurons exhibit a significant reduction in calcium influx via $\alpha 7-n A C h R s$ compared with the open-infected neurons (*** $p<0.0001$, Student's $t$ test). GPI $\alpha$ btx reduces the peak $\mathrm{Ca}^{2+}$ amplitude to the same extent as exogenously applied $\alpha$ btx and exogenous application of $\alpha$ btx does not further reduce peak calcium amplitude in GPl $\alpha$ btx-infected neurons. Values represent mean \pm SEM of results from $\geq 20$ neurons for each treatment from three separate experiments.

These results suggest that the activation of $\alpha 7-n A C h R s$ influences how neurons handle increases in $\left[\mathrm{Ca}^{2+}\right]_{\mathrm{i}}$.

Membrane-tethered $\alpha$ btx inhibits $\alpha$ 7-nAChR-mediated $\mathrm{Ca}^{2+}$ influx in ciliary ganglion neurons

To block $\mathrm{Ca}^{2+}$ influx via $\alpha 7-\mathrm{nAChRs}$ cell-autonomously in vivo, we used the avian retroviral vector RCASBP(A) to express an $\alpha$ btx that was modified at the $\mathrm{C}$ terminus to include a linker with a consensus sequence for the GPI linkage from mouse lynx-1 (Fig. 3A) (Ibanez-Tallon et al., 2004). Ciliary ganglion neurons infected with this construct exhibit bright, punctate $\alpha$ btx immunoreactivity on their cell surface, indicating efficient expression of tethered $\alpha$ btx (Fig. 3C). When the ciliary ganglion cultures are prepared from embryos infected with the control (open) virus, neurons do not label with $\alpha$ btx antibody (Fig. $3 B$ ). The specificity of $\alpha$ btx antibody was confirmed by Western blot and ELISA (sup- plemental Fig. 1, available at www.jneurosci.org as supplemental material).

To test whether GPI $\alpha$ btx blocks $\mathrm{Ca}^{2+}$ influx through $\alpha 7$ nAChRs, E8 ciliary ganglion neurons infected either with GPI $\alpha$ btx or open virus were subjected to $\mathrm{Ca}^{2+}$ imaging as described above. GPI $\alpha$ btx-infected neurons have significantly reduced nicotinic $\mathrm{Ca}^{2+}$ responses compared with the neurons infected with control virus (Fig. $3 D$ ) (open: $1.29 \pm 0.13, n=21$; GPI $\alpha$ btx: $0.36 \pm 0.06, n=23$; $p<0.0001$, Student's $t$ test). In fact, GPI $\alpha$ btx inhibits nicotine-induced increases in intracellular $\mathrm{Ca}^{2+}$ to the same extent as exogenously applied $\alpha$ btx (Fig. 3D) (open plus $\alpha$ btx: $0.19 \pm 0.04, n=7$; GPI $\alpha$ btx: $0.36 \pm 0.06, n=$ 23). Moreover, applying exogenous $\alpha$ btx ( $50 \mathrm{~nm}$ ) to GPI $\alpha$ btxinfected cultures does not cause additional reduction in $\mathrm{Ca}^{2+}$ influx (Fig. 3D) (GPI $\alpha$ btx: $0.36 \pm 0.06, n=23$; GPI $\alpha$ btx plus 50 nM $\alpha$ btx: $0.30 \pm 0.05, n=6)$. The above findings indicate that tethered $\alpha$ btx inhibits $\alpha 7$-nAChR-mediated increases in intracellular $\mathrm{Ca}^{2+}$

Expression of the GPI $\alpha$ btx does not eliminate all of the calcium influx, leaving behind the residual $\mathrm{Ca}^{2+}$ response (Fig. 3D), which is very similar to the residual response observed after a treatment with MLA (Fig. 2C). This residual response is eliminated by the treatment with $\mathrm{DH} \beta \mathrm{E}$ (Fig. $2 \mathrm{C}$ ), an antagonist that is more selective for heteromeric $\alpha 3^{*}$-nAChRs. Treatment of GPI $\alpha$ btx-infected neurons with exogenous $\alpha$ btx does not cause an additional reduction in the residual $\mathrm{Ca}^{2+}$ response (Fig. 3D).

To determine whether the GPI $\alpha$ btx can be spontaneously released from the surface of a neuron and bind to $\alpha 7$-nAChRs on nearby neurons, we coincubated uninfected ciliary ganglion neurons overnight with the neurons infected with the GPI $\alpha$ btx (Fig. 4). The cultures were then live-labeled with $\alpha$ btx-Alexa 488 to visualize unoccupied surface $\alpha 7$-nAChRs. Uninfected neurons label strongly with $\alpha$ btx-Alexa 488 , whereas neurons infected with GPI $\alpha$ btx retrovirus do not label with $\alpha$ btx-Alexa 488 (Fig. $4 B, C)$. Importantly, uninfected neurons that were coincubated with the GPI $\alpha$ btx-infected neurons still exhibit intense $\alpha$ btxAlexa 488 labeling that is comparable to uninfected controls (Fig. $4 D$ ), demonstrating that their $\alpha 7$-nAChRs are not occupied by $\alpha$ btx clipped off the surface of GPI $\alpha$ btx-infected neurons.

GPI $\alpha$ btx rescues ciliary and choroid neurons from cell death To block activation of $\alpha 7$-nAChRs on ciliary ganglion neurons in vivo, we infected chicken embryos with RCASBP(A)-GPI $\alpha$ btx and counted the number of surviving neurons at E14 using design-based stereology (Bunker and Nishi, 2002). If the viral particles are injected into the mesencephalon at stage $8-9$ (36 h of development), ciliary ganglion neurons precursors are still present at the neural tube and accessible to retroviral infection (Fig. 5A-C). However, if viral particles are injected at stage $10-$ 13 , the precursors have already migrated away from the neural tube to form a ganglion and are therefore inaccessible to the retrovirus, resulting in uninfected neurons surrounded by infected non-neuronal cells (Fig. 5D-F).

For counting purposes, ciliary ganglia were labeled with Islet-1 and somatostatin antibodies (Fig. 5G). Infection with GPI $\alpha$ btx at $36 \mathrm{~h}$ of development rescues $41 \%$ of ciliary ganglion neurons from cell death compared with control-infected ganglia (Fig. $5 H)(p<0.001$, ANOVA; open ganglia: 6459 neurons, $n=$ 6; GPI $\alpha$ btx ganglia: 11,310 neurons, $n=8$ ). Moreover, both ciliary $(p<0.01)$ and choroid neurons are rescued (Fig. $5 H$ ) $(p<0.001$, ANOVA with Tukey's multiple-comparison post hoc). When neurons are not infected, but surrounding nonneuronal cells are with RCASBP(A)-GPI $\alpha$ btx, then neuronal cell 
numbers are not significantly different from open-infected control ciliary ganglia (Fig. 5H) (GPI $\alpha$ btx ganglia infected at 48 h: 8250 neurons, $n=9)$. Thus, the GPI $\alpha$ btx must be expressed in ciliary ganglion neurons to block cell death. These results also show that GPI $\alpha$ btx is not released from cells in quantities sufficient to block $\alpha 7$-nAChRs on nearby neurons.

The ciliary ganglion receives preganglionic input from the accessory oculomotor nucleus (AON) in the midbrain. The preganglionic neurons also contain presynaptic $\alpha 7$-nAChRs that control the release of acetylcholine by increasing the $\mathrm{Ca}^{2+}$ influx into the presynaptic terminals (Coggan et al., 1997; Rogers and Sargent, 2003). Therefore, inhibition of these receptors with GPI $\alpha$ btx could also affect survival of ciliary ganglion neurons. However, p27gag immunoreactivity is observed only in a small number of $\mathrm{AON}$ neurons (Fig. 6A-C, arrows), indicating that preganglionic neurons do not express GPI $\alpha$ btx. Thus, presynaptic $\alpha 7$-nAChRs in terminals from $\mathrm{AON}$ are unlikely to affect survival of ciliary ganglion neurons.

\section{Discussion}

The principal findings reported here support the hypothesis that $\alpha 7$-nAChRs facilitate developmental cell death of parasympathetic neurons, possibly by allowing increases in intracellular calcium that exceed the threshold for cell survival. Shortly after all of the neurons in the ciliary ganglion are innervated by preganglionic inputs, neurons express variable levels of $\alpha 7-n A C h R s$ together with differences in $\alpha 7$-mediated increases in intracellular calcium induced by nicotine. Furthermore, intracellular increases in calcium fall to baseline levels at slower rates in young neurons compared with neurons that have survived the cell death period. Finally, cell-autonomous inhibition of $\alpha 7$-nAChR signaling prevents cell death. Thus, anterograde signals play an important role in sculpting the final number of neurons in the autonomic nervous system.

The conclusion that activation of $\alpha 7$-nAChRs on ciliary ganglion neurons facilitates normal neuronal loss in the ganglion is based on the cell-autonomous action of GPI $\alpha$ btx. The utility of this reagent in vivo was first demonstrated in zebrafish striated muscle; also in these studies, Xenopus oocytes expressing the GPI $\alpha$ btx coincubated with oocytes expressing $\alpha 7$-nAChRs did not block $\alpha 7$ responses, demonstrating that the toxin was not cleaved and acting non-cell autonomously (Ibanez-Tallon et al., 2004). We show similar results when neurons expressing GPI $\alpha$ btx are cocultured with uninfected neurons. Importantly, in vivo, we fail to rescue neurons when the GPI $\alpha$ btx is expressed only in surrounding non-neuronal cells; the construct must be in neurons to rescue them. However, at the present time we cannot distinguish between $\alpha 7$-nAChRs located in cell soma and the terminals of ciliary ganglion neurons. $\operatorname{RCASBP}(\mathrm{A})$ does not efficiently infect early neural progenitors in the neural tube, therefore GPI $\alpha$ btx is poorly expressed on the preganglionic neurons in the midbrain. Thus, presynaptic $\alpha 7-\mathrm{nAChRs}$ in GPI $\alpha$ btxinfected embryos are not affected. This observation excludes $\alpha 7$ -
nAChRs on neurons in the AON as a significant contributor to cell death of ciliary ganglion neurons.

The hypothesis that $\alpha 7$-nAChR activation facilitates cell death of ciliary ganglion neurons is consistent with the temporal sequence of ganglionic innervation. Afferents from the AON first make contact at E4.5, and the neurons are $100 \%$ functionally innervated by E8, before the onset of cell loss (Landmesser and Pilar, 1972, 1974a). Our flow cytometry and calcium imaging data confirm and extend previous observations that ciliary ganglion neurons express many $\alpha 7$ receptors by E8 (Corriveau and Berg, 1993; Blumenthal et al., 1999; Brumwell et al., 2002). Whether the AON is spontaneously active at such early times is not clear; however, spontaneous electrical activity in the brainstem is detected using optical recording techniques at very early stages of embryonic development (Momose-Sato et al., 2003; Sato and Momose-Sato, 2003). In addition, ciliary neurons are enveloped in a preganglionic calyx at E8 that may serve to trap acetylcholine, bringing it to high levels if extracellular esterase activity is low. Finally, the kinetics of $\alpha 7-\mathrm{nAChR}$ inactivation at E8 versus E13 have yet to be examined. It is plausible that $\alpha 7$ nAChRs at E8 inactivate more slowly than more mature receptors.

The molecular mechanism underlying $\alpha 7$-nAChR effects on survival is likely to involve $\mathrm{Ca}^{2+}$ as an activator of cell death. $\mathrm{Ca}^{2+}$ is an intracellular messenger that operates over a wide temporal and spatial range to regulate many different cellular processes, and $\mathrm{Ca}^{2+}$ overload has been suggested to be the final common pathway of all types of cell death (Berridge et al., 2003; Hajnoczky et al., 2003; Rizzuto et al., 2003). $\alpha 7$-nAChRs have very high relative permeability to $\mathrm{Ca}^{2+}$ that is comparable to that of NMDA receptors. Furthermore, $\alpha 7$-nAChRs are insensitive to $\mathrm{Mg}^{2+}$ blockade, which allows them to mediate $\mathrm{Ca}^{2+}$ influx at rest (Role and Berg, 1996; Berg and Conroy, 2002). Therefore, we propose that activation of $\alpha 7-n A C h R s$ can increase $\left[\mathrm{Ca}^{2+}\right]_{\mathrm{i}}$ to the levels that can be toxic to immature neurons. In support of this, a naturally occurring mutation in the $\alpha 7-\mathrm{nAChR}$ homolog induces cell death in Caenorhabditis elegans because of increased 

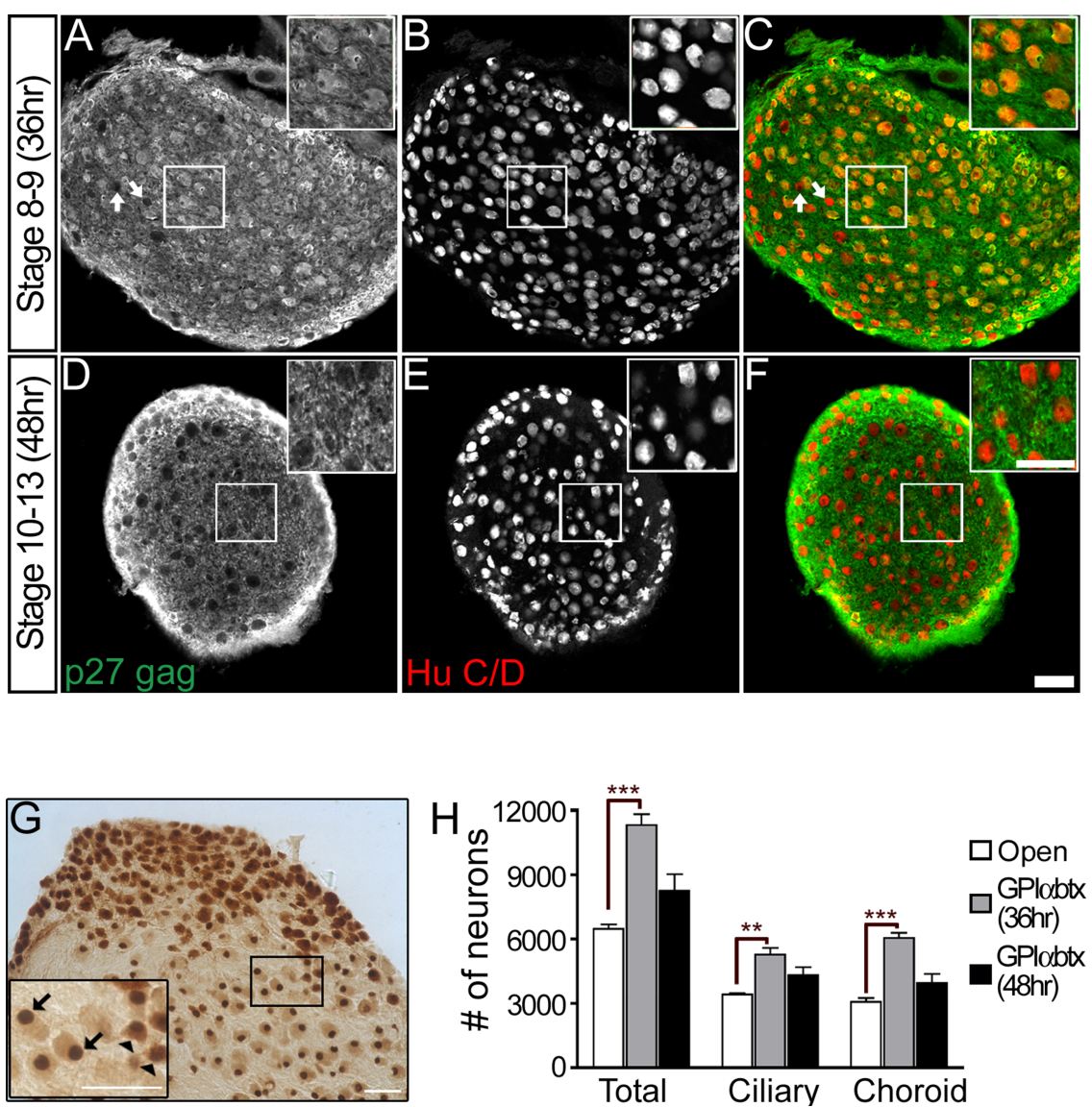

Figure 5. Cell-autonomous inhibition with $\mathrm{GPI} \alpha \mathrm{btx}$ rescues ciliary ganglion neurons from cell death. $\boldsymbol{A}-\boldsymbol{F}$, Embryos were infected with open RCASBP(A) or RCASBP(A)-GPl $\alpha$ btx at $36 \mathrm{~h}$ of development (stage $8-9 ; A-C$ ) or $48 \mathrm{~h}$ of development (stage $10-13 ; \boldsymbol{D}-\boldsymbol{F}$ ). Immunoreactivity for p27gag (green) is observed in neurons (red) of ciliary ganglia from embryos infected at stage $8-9$ ( $A, C$; arrows indicate few uninfected neurons), whereas only surrounding non-neural tissue is immunoreactive for p27gag in embryos infected at stage 10-13 (D, F). Scale bars: (in $\boldsymbol{F}) 200 \mu \mathrm{m}$; inset, $50 \mu \mathrm{m}$. G, Serially sectioned E14 ganglia were labeled with neuronal-specific Islet-1 antibody (nuclear; arrows) and somatostatin antibody (cytoplasmic; arrowheads) to identify choroid neurons. Scale bars, $50 \mu \mathrm{m}$. $\boldsymbol{H}$, The total number of neurons (Islet-1 positive) and the number of choroid neurons (somatostatin positive) in sections stained as in $\boldsymbol{G}$ were counted by design-based stereology, and the number of ciliary neurons was inferred by subtracting the number of choroid neurons from the total. Expression of $\mathrm{GPI} \alpha$ btx prevents cell death of ciliary $\left({ }^{* *} p<0.01\right.$, one-way ANOVA) and choroid ( ${ }^{* * *} p<0.001$, one-way ANOVA) neurons. Expression of GPI $\alpha$ btx only in surrounding non-neural tissues does not prevent cell death. Values represent mean \pm SEM.
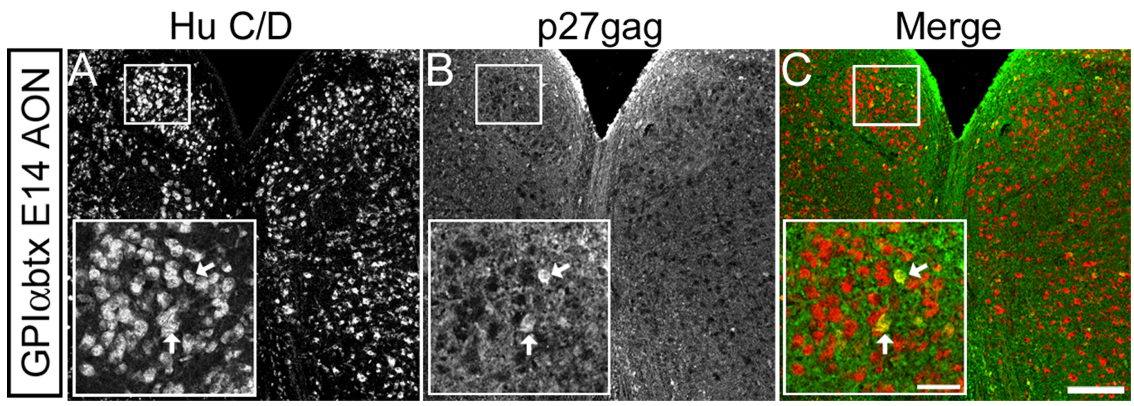

Figure 6. Presynaptic $\alpha 7$-nAChRs from AON are unlikely to mediate death of ciliary ganglion neurons. $\boldsymbol{A}$, Neurons in the preganglionic AON from embryos infected at stage $8-9$ were identified with $\mathrm{Hu} C / D$ antibody. $B$, Only surrounding glia, but not Hu C/D-positive cells, label with p27gag antibody, indicating that AON neurons are not infected. C, Overlay of the Hu C/D immunoreactivity (red) with the p27gag immunoreactivity (green). Only a few neurons show p27gag immunoreactivity (arrows). Scale bars: (in C) $200 \mu \mathrm{m}$; inset, $50 \mu \mathrm{m}$.

$\mathrm{Ca}^{2+}$ influx entering via slowly desensitizing receptors (Treinin and Chalfie, 1995). Transgenic mice homozygous for a similar gain-of-function mutation in $\alpha 7$-nAChRs also exhibit widespread neuronal apoptosis (Orr-Urtreger et al., 2000). Furtherganglion. Pan-nicotinic antagonists such as chlorisondamine, pempidine, or D-tubocurare reduce survival of ciliary ganglion neurons (Wright, 1981; Meriney et al., 1987; Maderdrut et al., 1988). Furthermore, removal of afferent input to the ciliary gan-

more, $\mathrm{Ca}^{2+}$ influx caused by activation of $\alpha 7$-nAChRs induced apoptotic cell death in undifferentiated and immortalized hippocampal progenitor cells but not in differentiated cells (Berger et al., 1998). These progenitor cells were susceptible to $\mathrm{Ca}^{2+}$ overload because of their lack of buffering capability, whereas more mature neurons upregulated the expression of calbindin and no longer died as a result of $\alpha 7-\mathrm{nAChR}$ activation. In line with this evidence, ciliary ganglion neurons generate significantly larger increases in $\left[\mathrm{Ca}^{2+}\right]_{\mathrm{i}}$ in response to nicotine at $\mathrm{E} 8$ than at $\mathrm{E} 9$. In addition, after nicotine stimulation, E8 neurons exhibit a slower rate of intracellular $\mathrm{Ca}^{2+}$ decay than E13 neurons. Thus, E8 neurons with a large response to nicotine are likely to be more vulnerable to $\mathrm{Ca}^{2+}$ influx through $\alpha 7$-nAChRs.

What prevents $\alpha 7$-nAChRs from triggering cell death after the final number of neurons is established? In mature neurons, multiple factors control expression and signaling via $\alpha 7$-nAChRs, thus protecting neurons from large, global increases in $\left[\mathrm{Ca}^{2+}\right]_{\mathrm{i}}$. For example, mature ciliary neurons cluster $\alpha 7$-nAChRs on somatic spines (Shoop et al., 2001, 2002), narrowing the spatial signaling range of $\mathrm{Ca}^{2+}$ to somatic spines, where it can be handled regionally. Furthermore, $\alpha 7$-nAChRs on mature neurons are excluded from postsynaptic densities and therefore are less likely to be activated by the release of acetylcholine from presynaptic terminals (Jacob and Berg, 1983; Horch and Sargent, 1995). Both types of neurons contain a large number of silent $\alpha 7$-nAChRs, suggesting that the majority of $\alpha 7$-nAChRs are normally prevented from signaling and are recruited only in special circumstances (McNerney et al., 2000). In addition, ciliary neurotrophic factor (CNTF), which is expressed by ciliary ganglion target tissues, downregulates the expression of $\alpha 7-n A C h R s$ (Halvorsen and Berg, 1989). Finally, endogenous neurotoxin-like molecules such as lynx1 are emerging as important modulators of $\alpha 7$ nAChR function (Miwa et al., 1999; IbanezTallon et al., 2002). In fact, ciliary ganglion neurons turn on expression of the lynxrelated gene during the period of cell loss, which reduces the $\mathrm{Ca}^{2+}$ influx through $\alpha 7$ nAChRs receptors (Nishi et al., 2006).

Other studies with pharmacological agents that block nicotinic signaling differ from our conclusion that inhibition of $\alpha 7$ $\mathrm{nAChRs}$ prevents cell death in the ciliary 
glion exacerbates cell death (Furber et al., 1987). These studies together with some cell culture models indicate that depolarization and increases in $\left[\mathrm{Ca}^{2+}\right]_{\mathrm{i}}$ normally enhance survival of ciliary ganglion neurons (Pugh and Margiotta, 2000). However, increases in intracellular-free calcium can be either survival promoting or death inducing, depending on the $\mathrm{Ca}^{2+}$ set-point of a neuron (Johnson et al., 1992; Ghosh and Greenberg, 1995). Therefore, excessive increases in intracellular $\mathrm{Ca}^{2+}$ via $\alpha 7$ nAChRs could exceed threshold for an optimal $\mathrm{Ca}^{2+}$ set-point and induce cell death, whereas moderate increases in intracellular $\mathrm{Ca}^{2+}$ are survival promoting. To this end, we showed that individual E8 ciliary ganglion neurons express heterogeneous levels of $\alpha 7$-nAChRs on their surface. As a result, some neurons display very large increases in $\left[\mathrm{Ca}^{2+}\right]_{i}$, whereas others exhibit a much smaller elevation in $\left[\mathrm{Ca}^{2+}\right]_{\mathrm{i}}$ via $\alpha 7$-nAChRs. Therefore, we propose that the neurons that die as a result of $\alpha 7-\mathrm{nAChR}$ activation are the ones that express high levels of surface $\alpha 7-\mathrm{nAChRs}$ and generate large $\left[\mathrm{Ca}^{2+}\right]_{\mathrm{i}}$ that exceed the set-point for cell death. Furthermore, activation of heteromeric $\alpha 3 / \beta 4 \mathrm{nAChRs,} \mathrm{which} \mathrm{is}$ the second type of nAChRs in the ciliary ganglion, leads to smaller increases in $\left[\mathrm{Ca}^{2+}\right]_{\mathrm{i}}$ that could be survival promoting. Thus, the balance between death-inducing signals via $\alpha 7-n A C h R s$ and survival-promoting signals via $\alpha 3^{\star}$-nAChRs could determine which neurons die and which neurons survive.

Although our findings demonstrate that anterograde signaling via $\alpha 7$-nAChRs influence the survival of ciliary ganglion neurons, they do not invalidate the neurotrophic hypothesis. In fact, inhibition of $\alpha 7$-nAChRs with membrane-tethered $\alpha$ btx rescues only $41 \%$ of neurons from dying, which argues that $\alpha 7$-nAChRs are not solely responsible for cell death of the ciliary ganglion neurons. Actually, ciliary ganglion neurons depend on CNTF for survival in vitro and in vivo, and overexpression of CNTF in chicken embryos rescues $31 \%$ of ciliary ganglion neurons that would have normally died in vivo (Nishi and Berg, 1979, 1981; Finn et al., 1998). Therefore, we propose that the balance between death-inducing and survival-promoting factors determines the final numbers of neurons in the ganglion. Initially, death signals predominate, which is evidenced by large programmed cell death at E6, several days before the actual decrement in cell number and synaptogenesis with the target tissues (Lee et al., 2001). As neurons extend processes and synapse with their targets, they become dependent on CNTF, which opposes the deleterious effects of $\alpha 7$-nAChRs by downregulating their expression (Halvorsen and Berg, 1989) or upregulating modulators of nAChR function such as lynx-1. In conclusion, our results highlight the importance of nontraditional roles of nAChRs during neural development.

\section{References}

Alkondon M, Pereira EF, Wonnacott S, Albuquerque EX (1992) Blockade of nicotinic currents in hippocampal neurons defines methyllycaconitine as a potent and specific receptor antagonist. Mol Pharmacol 41:802-808.

Berg DK, Conroy WG (2002) Nicotinic alpha 7 receptors: synaptic options and downstream signaling in neurons. J Neurobiol 53:512-523.

Berger F, Gage FH, Vijayaraghavan S (1998) Nicotinic receptor-induced apoptotic cell death of hippocampal progenitor cells. J Neurosci 18:6871-6881.

Berridge MJ, Bootman MD, Roderick HL (2003) Calcium signalling: dynamics, homeostasis and remodelling. Nat Rev Mol Cell Biol 4:517-529.

Bertrand D, Bertrand S, Ballivet M (1992) Pharmacological properties of the homomeric alpha 7 receptor. Neurosci Lett 146:87-90.

Blumenthal EM, Shoop RD, Berg DK (1999) Developmental changes in the nicotinic responses of ciliary ganglion neurons. J Neurophysiol $81: 111-120$.

Brumwell CL, Johnson JL, Jacob MH (2002) Extrasynaptic $\alpha 7$-nicotinic acetylcholine receptor expression in developing neurons is regulated by inputs, targets, and activity. J Neurosci 22:8101-8109.

Bunker GL, Nishi R (2002) Developmental cell death in vivo: rescue of neurons independently of changes at target tissues. J Comp Neurol 452:80-92.

Chang KT, Berg DK (1999) Nicotinic acetylcholine receptors containing $\alpha 7$ subunits are required for reliable synaptic transmission in situ. J Neurosci 19:3701-3710.

Chang KT, Berg DK (2001) Voltage-gated channels block nicotinic regulation of CREB phosphorylation and gene expression in neurons. Neuron 32:855-865.

Coggan JS, Paysan J, Conroy WG, Berg DK (1997) Direct recording of nicotinic responses in presynaptic nerve terminals. J Neurosci 17:5798-5806.

Corriveau RA, Berg DK (1993) Coexpression of multiple acetylcholine receptor genes in neurons: quantification of transcripts during development. J Neurosci 13:2662-2671.

Coulombe JN, Schwall R, Parent AS, Eckenstein FP, Nishi R (1993) Induction of somatostatin immunoreactivity in cultured ciliary ganglion neurons by activin in choroid cell-conditioned medium. Neuron 10:899-906.

Davies AM (1996) The neurotrophic hypothesis: where does it stand? Philos Trans R Soc Lond B Biol Sci 351:389-394.

Eisen JS, Melancon E (2001) Interactions with identified muscle cells break motoneuron equivalence in embryonic zebrafish. Nat Neurosci 4:1065-1070.

Epstein ML, Davis JP, Gellman LE, Lamb JR, Dahl JL (1988) Cholinergic neurons of the chicken ciliary ganglion contain somatostatin. Neuroscience 25:1053-1060.

Federspiel MJ, Hughes SH (1997) Retroviral gene delivery. Methods Cell Biol 52:179-214.

Finn TP, Kim S, Nishi R (1998) Overexpression of ciliary neurotrophic factor in vivo rescues chick ciliary ganglion neurons from cell death. J Neurobiol 34:283-293.

Furber S, Oppenheim RW, Prevette D (1987) Naturally-occurring neuron death in the ciliary ganglion of the chick embryo following removal of preganglionic input: evidence for the role of afferents in ganglion cell survival. J Neurosci 7:1816-1832.

Ghosh A, Greenberg ME (1995) Calcium signaling in neurons: molecular mechanisms and cellular consequences. Science 268:239-247.

Hajnoczky G, Davies E, Madesh M (2003) Calcium signaling and apoptosis. Biochem Biophys Res Commun 304:445-454.

Halvorsen SW, Berg DK (1989) Specific down-regulation of the $\alpha$-bungarotoxin binding component on chick autonomic neurons by ciliary neuronotrophic factor. J Neurosci 9:3673-3680.

Horch HL, Sargent PB (1995) Perisynaptic surface distribution of multiple classes of nicotinic acetylcholine receptors on neurons in the chicken ciliary ganglion. J Neurosci 15:7778-7795.

Ibanez-Tallon I, Miwa JM, Wang HL, Adams NC, Crabtree GW, Sine SM, Heintz N (2002) Novel modulation of neuronal nicotinic acetylcholine receptors by association with the endogenous prototoxin lynx1. Neuron 33:893-903.

Ibanez-Tallon I, Wen H, Miwa JM, Xing J, Tekinay AB, Ono F, Brehm P, Heintz N (2004) Tethering naturally occurring peptide toxins for cellautonomous modulation of ion channels and receptors in vivo. Neuron 43:305-311.

Jacob MH, Berg DK (1983) The ultrastructural localization of $\alpha$-bungarotoxin binding sites in relation to synapses on chick ciliary ganglion neurons. J Neurosci 3:260-271.

Johnson Jr EM, Koike T, Franklin J (1992) A “calcium set-point hypothesis" of neuronal dependence on neurotrophic factor. Exp Neurol 115:163-166.

Landmesser L, Pilar G (1972) The onset and development of transmission in the chick ciliary ganglion. J Physiol (Lond) 222:691-713.

Landmesser L, Pilar G (1974a) Synapse formation during embryogenesison ganglion cells lacking the periphery. J Physiol (Lond) 241:715-736.

Landmesser L, Pilar G (1974b) Synaptic transmission and cell death during normal ganglionic development. J Physiol (Lond) 241:737-749.

Lee VM, Smiley GG, Nishi R (2001) Cell death and neuronal replacement during formation of the avian ciliary ganglion. Dev Biol 233:437-448.

Liu Z, Neff RA, Berg DK (2006) Sequential interplay of nicotinic and 
GABAergic signaling guides neuronal development. Science 314:1610-1613.

Maderdrut JL, Oppenheim RW, Prevette D (1988) Enhancement of naturally occurring cell death in the sympathetic and parasympathetic ganglia of the chicken embryo following blockade of ganglionic transmission. Brain Res 444:189-194.

Marusich MF, Weston JA (1992) Identification of early neurogenic cells in the neural crest lineage. Dev Biol 149:295-306.

Marwitt R, Pilar G, Weakly JN (1971) Characterization of two ganglion cell populations in avian ciliary ganglia. Brain Res 25:317-334.

McNerney ME, Pardi D, Pugh PC, Nai Q, Margiotta JF (2000) Expression and channel properties of alpha-bungarotoxin-sensitive acetylcholine receptors on chick ciliary and choroid neurons. J Neurophysiol 84:1314-1329.

Meriney SD, Pilar G, Ogawa M, Nunez R (1987) Differential neuronal survival in the avian ciliary ganglion after chronic acetylcholine receptor blockade. J Neurosci 7:3840-3849.

Miwa JM, Ibanez-Tallon I, Crabtree GW, Sanchez R, Sali A, Role LW, Heintz N (1999) lynxl, an endogenous toxin-like modulator of nicotinic acetylcholine receptors in the mammalian CNS. Neuron 23:105-114.

Momose-Sato Y, Mochida H, Sasaki S, Sato K (2003) Depolarization waves in the embryonic CNS triggered by multiple sensory inputs and spontaneous activity: optical imaging with a voltage-sensitive dye. Neuroscience 116:407-423.

Morgan BA, Fekete DM (1996) Manipulating gene expression with replication-competent retroviruses. Methods Cell Biol 51:185-218.

Nishi R (1996) Autonomic and sensory neuron cultures. Methods Cell Biol 51:249-263.

Nishi R, Berg DK (1979) Survival and development of ciliary ganglion neurones grown alone in cell culture. Nature 277:232-234.

Nishi R, Berg DK (1981) Two components from eye tissue that differentially stimulate the growth and development of ciliary ganglion neurons in cell culture. J Neurosci 1:505-513.

Nishi R, Hruska M, Keefe J, Tekinay AB, Ibanez-Tallon I (2006) Chicken lynx: a developmentally regulated GPI-linked molecule in the avian ciliary ganglion that reduces calcium flux through $\alpha 7$ nicotinic acetylcholine receptors and prevents cell death. Soc Neurosci Abstr 36:322.9.

Oppenheim RW (1991) Cell death during development of the nervous system. Annu Rev Neurosci 14:453-501.

Orr-Urtreger A, Broide RS, Kasten MR, Dang H, Dani JA, Beaudet AL, Patrick JW (2000) Mice homozygous for the L250T mutation in the alpha7 nicotinic acetylcholine receptor show increased neuronal apoptosis and die within 1 day of birth. J Neurochem 74:2154-2166.

Pettmann B, Henderson CE (1998) Neuronal cell death. Neuron 20:633-647.

Potts WM, Olsen M, Boettiger D, Vogt VM (1987) Epitope mapping of monoclonal antibodies to gag protein p19 of avian sarcoma and leukaemia viruses. J Gen Virol 68:3177-3182.

Pugh PC, Berg DK (1994) Neuronal acetylcholine receptors that bind $\alpha$-bungarotoxin mediate neurite retraction in a calcium-dependent manner. J Neurosci 14:889-896.

Pugh PC, Margiotta JF (2000) Nicotinic acetylcholine receptor agonists promote survival and reduce apoptosis of chick ciliary ganglion neurons. Mol Cell Neurosci 15:113-122.

Rizzuto R, Pinton P, Ferrari D, Chami M, Szabadkai G, Magalhaes PJ, Di Virgilio F, Pozzan T (2003) Calcium and apoptosis: facts and hypotheses. Oncogene 22:8619-8627.

Rogers M, Sargent PB (2003) Rapid activation of presynaptic nicotinic acetylcholine receptors by nerve-released transmitter. Eur J Neurosci 18:2946-2956.

Rohrer H, Henke-Fahle S, el-Sharkawy T, Lux HD, Thoenen H (1985) Progenitor cells from embryonic chick dorsal root ganglia differentiate in vitro to neurons: biochemical and electrophysiological evidence. EMBO J 4:1709-1714.

Role LW, Berg DK (1996) Nicotinic receptors in the development and modulation of CNS synapses. Neuron 16:1077-1085.

Sato K, Momose-Sato Y (2003) Optical detection of developmental origin of synaptic function in the embryonic chick vestibulocochlear nuclei. J Neurophysiol 89:3215-3224.

Shoop RD, Berg DK (1999) Developmental changes in the nicotinic responses of ciliary ganglion neurons. J Neurophysiol 81:111-120.

Shoop RD, Chang KT, Ellisman MH, Berg DK (2001) Synaptically driven calcium transients via nicotinic receptors on somatic spines. J Neurosci 21:771-781.

Shoop RD, Esquenazi E, Yamada N, Ellisman MH, Berg DK (2002) Ultrastructure of a somatic spine mat for nicotinic signaling in neurons. J Neurosci 22:748-756.

Snider WD (1994) Functions of the neurotrophins during nervous system development: what the knockouts are teaching us. Cell 77:627-638.

Treinin M, Chalfie M (1995) A mutated acetylcholine receptor subunit causes neuronal degeneration in C. elegans. Neuron 14:871-877.

Wang L, Galehouse D, Mellon P, Duesberg P, Mason WS, Vogt PK (1976) Mapping oligonucleotides of Rous sarcoma virus RNA that segregate with polymerase and group-specific antigen markers in recombinants. Proc Natl Acad Sci USA 73:3952-3956.

Wright L (1981) Cell survival in chick embryo ciliary ganglion is reduced by chronic ganglionic blockade. Brain Res 227:283-286.

Zhang ZW, Coggan JS, Berg DK (1996) Synaptic currents generated by neuronal acetylcholine receptors sensitive to alpha-bungarotoxin. Neuron 17:1231-1240.

Zheng JQ, Felder M, Connor JA, Poo MM (1994) Turning of nerve growth cones induced by neurotransmitters. Nature 368:140-144. 